\section{Addition of Forchlorfenuron to Spray Pollination Media Increases Fruit Set in 'Hosui' Japanese Pear}

\author{
Daisuke Sakamoto $^{1}$, Shinnosuke Kusaba ${ }^{1}$, and Yuri Nakamura ${ }^{2,3}$
}

ADDITIONAL INDEX wORDS. CPPU, labor-saving pollination, parthenocarpic properties, pollen grain viability, Pyrus pyrifolia, suspension medium

SuMMARY. The effects on fruit set of adding forchlorfenuron (CPPU) to media in which pollen grains were suspended and used for spray pollination was investigated in 'Hosui' japanese pear (Pyrus pyrifolia). The percentages of fruit set after spray pollination were lower than those after hand pollination; however, media with 2 or $10 \mathrm{mg} \cdot \mathrm{L}^{-1} \mathrm{CPPU}$ used for spray pollination resulted in greater percentages of fruit set than media without CPPU. The media with CPPU also resulted in higher levels of pollen germination compared with the medium without CPPU; however, the number of seeds per fruit with CPPU treatment tended to be almost the same or less than for fruit without CPPU treatment. From these results, the higher levels of fruit set by CPPU might not be due to the high germination rate of the pollen grains but due to the induction of partial parthenocarpic properties. The medium with $10 \mathrm{mg} \cdot \mathrm{L}^{-1}$ CPPU gave the highest levels of fruit set, but the fruit had abnormally thickened and enlarged calyxes, and the fruit shape tended to be deformed at $\approx 21$ days after flowering. In addition, all of the harvested fruit were calyx-perpetual fruit in which the calyx remains until harvest time. Fruit treated with $2 \mathrm{mg} \cdot \mathrm{L}^{-1} \mathrm{CPPU}$ also yielded calyx-perpetual fruit with high frequency, but the fruit had normal calyxes and the fruit shape tended to be more normal. Thus, we conducted experiments focusing on the medium containing $2 \mathrm{mg} \cdot \mathrm{L}^{-1} \mathrm{CPPU}$. Although the results were variable from year to year, more than $70 \%$ of hand-pollinated flowers set fruit during the 3-year study; this level of fruit production is sufficient for practical use. Thus, spray pollination using a medium with $2 \mathrm{mg} \cdot \mathrm{L}^{-1} \mathrm{CPPU}$ is an acceptable method for pollinating 'Hosui' japanese pear.

$\mathrm{J}$ apanese pear is one of the most important fruit crops in Japan. Most cultivars of japanese pear are self-incompatible (Sakamoto et al., 2009). In general, artificial pollination by hand using compatible pollen with a conventional feathered stick is used for commercial production in Japan. However, the effective period for artificial pollination is limited during the flowering period. In addition, the success of hand pollination is dependent on environmental factors such as air temperature, wind, and rainfall. Furthermore, hand pollination is a laborintensive process resulting in high labor costs. As an alternative, a spray pollination technique using aqueous pollen grain solutions is expected to reduce labor and other costs associated with fruit tree cultivation. In kiwifruit, a practical technique was successfully established through the development of a pollen grain suspension medium

${ }^{1}$ NARO Institute of Fruit Tree Science, Tsukuba, Ibaraki 305-8605, Japan

${ }^{2}$ NARO Headquarters, Tsukuba, Ibaraki 305-8517, Japan

${ }^{3}$ Corresponding author. E-mail: kunugi@affrc.go.jp.
(Hopping and Simpson, 1982). More recently, a liquid pollen grain suspension medium thickened with agar was also developed for kiwifruit [Actinidia chinensis (Yano et al., 2007)]. In the case of japanese pear, a practical spray pollination technique for 'Kosui', the most popular cultivar in Japan, was successfully established and has been useful for reducing both material and labor costs (Sakamoto et al., 2009). However, fruit set using spray pollination varied among cultivars. The level of fruit set in 'Akizuki' and 'Shuurei' after spray pollination was almost the same as 'Kosui' $[\approx 67 \%$ to $97 \%$ of handpollinated fruit (Sakamoto et al., 2014)], but 'Hosui' and 'Niitaka' yielded poor fruit set (less than $50 \%$ of handpollinated fruit) with the same medium as used for 'Kosui' (Naoyuki Hiura, personal communication). Therefore, a practical cultivar(s)-specific spray pollination technique needed to be developed.

The high fruit set of 'Kosui', 'Akizuki', and 'Shuurei' obtained by spray pollination may be due to the partial parthenocarpic properties of these cultivars (Sakamoto et al., 2009, 2014). Treatments with gibberellin and/or CPPU induce parthenocarpic properties in several fruit (Sotomayor et al., 2012; Watanabe et al., 2008), but gibberellin also inhibits pollen germination in grape [Vitis vinifera (Ohara et al., 2005)]. Also, CPPU application before and during the flowering period induced partial parthenocarpic properties and resulted in higher levels of fruit set compared with no pollination in japanese pear, apple (Malus pumila), and kiwifruit (Ainalidou et al., 2015; Niu et al., 2015; Zhang et al., 2008).

Based on these factors, we investigated the effects of CPPU on pollen grain germination and its influences on fruit set and fruit quality to establish a spray pollination protocol in which more than $70 \%$ of hand-pollinated flowers would set fruit in Hosui, the second most popular japanese pear cultivar in Japan.

\section{Materials and methods}

EFFECTS OF CPPU ON POLLEN GRAIN VIABILITY. The pollen grains used for all experiments in this study were prepared as follows. Purified pollen grains of 'Xue Hua Li' stored a few years in a deep freezer $\left(-30{ }^{\circ} \mathrm{C}\right)$ were used. Before use, purified pollen grains were acclimatized for $2 \mathrm{~h}$ at $15{ }^{\circ} \mathrm{C}, 100 \%$ relative humidity. Before performing spray pollination experiments in the field, we carried out pollen germination tests to assess the effects of CPPU on pollen grain viability. The acclimatized pollen grains were suspended at $0.3 \%(\mathrm{w} / \mathrm{v})$ in media containing $10 \%(\mathrm{w} / \mathrm{v})$ sucrose and $0.1 \%(\mathrm{w} / \mathrm{v})$ agar supplemented with 0,2 , or $10 \mathrm{mg} \cdot \mathrm{L}^{-1}$ of CPPU (Kyowa Hakko Bio Co., Tokyo, Japan). These suspension media were kept at

\begin{tabular}{llll}
\hline $\begin{array}{l}\text { Units } \\
\begin{array}{l}\text { To convert U.S. to SI, } \\
\text { multiply by }\end{array}\end{array}$ & U.S. unit & SI unit & $\begin{array}{l}\text { To convert SI to U.S., } \\
\text { multiply by }\end{array}$ \\
\hline 29.5735 & $\mathrm{fl} \mathrm{oz}$ & $\mathrm{mL}$ & 0.0338 \\
28.3495 & $\mathrm{oz}$ & $\mathrm{g}$ & 0.0353 \\
1 & $\mathrm{ppm}$ & $\mathrm{mg} \cdot \mathrm{L}^{-1}$ & 1 \\
$\left({ }^{\circ} \mathrm{F}-32\right) \div 1.8$ & ${ }^{\circ} \mathrm{F}$ & ${ }^{\circ} \mathrm{C}$ & $\left({ }^{\circ} \mathrm{C} \times 1.8\right)+32$
\end{tabular}


$20{ }^{\circ} \mathrm{C}$ for $0.5, \mathrm{l}$, and $2 \mathrm{~h}$. Aliquots $(0.2 \mathrm{~mL})$ of each suspension medium were subsequently spread on the surfaces of agar plates [ $1 \%(\mathrm{w} / \mathrm{v})$ agar and $10 \%(\mathrm{w} / \mathrm{v})$ sucrose $]$ and the number of germinated pollen were counted after $2 \mathrm{~h}$ at $25^{\circ} \mathrm{C}$ as described by Yano et al. (2007). As a control, pollen grains (not in medium) kept at $20^{\circ} \mathrm{C}$ for 0 and $2 \mathrm{~h}$ were also used in the pollen germination test as a control. Three plates were used for each treatment. The germination rates were assessed using a light microscope (Digital Fine Scope VC3500; Omron, Kyoto, Japan). The germination rate was determined from $\approx 100$ pollen grains in each of three areas per plate.

SPRAY POLLINATION EXPERIMENTS IN THE FIELD. Field pollination experiments were performed in 2010, 2012, and 2013 at the National Institute of Fruit Tree Science (Ibaraki, Japan) using four (2010) and three (2012 and 2013) mature trees of 'Hosui' japanese pear. Pollen grains were acclimated and then suspended in media at a concentration of $0.3 \%$ $(\mathrm{w} / \mathrm{v})$. Details of the media used for the spray pollination experiments are shown in the next section. Spray pollination was carried out using a hand sprayer provided by Furupra (Tokyo, Japan). As a positive control, pollen grains diluted to $1 / 5(\mathrm{w} / \mathrm{w})$ with lycopodium (Lycopodium clavatum) spores were used for hand pollination using a conventional feathered stick. A total of 60 flower clusters were used for each treatment. Fifteen individual flower clusters were selected for each treatment per tree (four trees) in 2010, and 20 individual flower clusters for each treatment per tree (three trees) were selected in 2012 and 2013. Similar treatments were applied to flower clusters on the same tree but not to flower clusters on the same bearing shoot. Since each flower cluster contained 8 to 10 flowers, we reduced the number of flowers to 5 flowers/cluster by removing extra flowers at the balloon stage. Then, each flower cluster was covered with a paper bag to avoid natural pollination. Pollinations were carried out at the time of flowering, and the treated flowers were again covered with bags for $\approx 3$ weeks. Air temperatures during the pollination treatments were $17.9^{\circ} \mathrm{C}$ in $2010,16.9^{\circ} \mathrm{C}$ in 2012 , and $17.4^{\circ} \mathrm{C}$ in 2013 , and the average air temperatures 1 week after pollination were $10.0{ }^{\circ} \mathrm{C}$ in 2010 ,
$12.6{ }^{\circ} \mathrm{C}$ in 2012 , and $12.2{ }^{\circ} \mathrm{C}$ in 2013 , respectively. We also included a set of flower clusters that were not pollinated to be used as negative controls for determining fruit and seed set, and fruit quality.

SUSPENSION MEDIA FOR SPRAY POLLINATION. All media contained $10 \%(\mathrm{w} / \mathrm{v})$ sucrose to prevent the pollen grains from bursting due to osmotic shock. Agar at $0.1 \%(\mathrm{w} / \mathrm{v})$ was used to improve the dispersion of pollen and the viscosity of the media according to the method of Sakamoto et al. (2009). As shown in Table 1 , three kinds of media supplemented with 0,2 , and $10 \mathrm{mg} \cdot \mathrm{L}^{-1}$ of CPPU were used in the 2010 experiment. In 2012 and 2013, two kinds of media supplemented with 0 and $2 \mathrm{mg} \cdot \mathrm{L}^{-1}$ of CPPU were used in the experiments. In 2013, a medium supplemented with $2 \mathrm{mg} \cdot \mathrm{L}^{-1}$ of CPPU and containing no pollen grains was used for the experiment in addition to the above described set of conditions. In parallel with the pollination experiments in the field, the germination rates of pollen in all media were checked at the beginning and the end of each pollination procedure (pollination experiments took $\approx 3 \mathrm{~h}$ ) by the pollen germination test, as described above. The germination rates of the pollen used for hand pollination were also checked.

EvalUATING THE EFFECTS OF THE SUSPENSION MEDIA ON FRUIT SET AND FRUIT QUALITY. The percentages of fruit set were determined $\approx 21 \mathrm{~d}$ after flowering. After measuring fruit set, fruit was thinned to one fruit per flower cluster, and the fruit load per branch was adjusted with fruit that were not used for the study according to the usual commercial practices in Japan. Fruit from all treatments were harvested during the normal commercial harvest period, from the end of August to the middle of September. The quality of all harvested fruit for each treatment was assessed as follows. Fruit weight, the index of irregular fruit shape (calculated using the ratio of maximum width to height of the fruit), and the number of seeds per fruit were determined. Total soluble solids (percent) and the $\mathrm{pH}$ of juice extracted from the flesh at opposite sides of the fruit were determined using a refractometer (PR-101 $\alpha$; Atago, Tokyo, Japan) and a pH meter (twin pH B-212; Horiba, Kyoto, Japan), respectively. In the CPPU treatment without pollen, only eight fruit were harvested. For other treatments, 35-57 fruit per treatment were harvested.

The data were analyzed by a oneway analysis of variance for each year and tested for significant differences among treatments by Tukey-Kramer test at $P<0.05$.

\section{Results and discussion}

EFFECT OF CPPU ON POLLEN GRAIN GERMINATION. Before performing spray pollination experiments in the field, we carried out pollen germination tests to assess the effects of CPPU on pollen grain viability. The pollen germination rate of pollen grains (no medium) kept at $20.0^{\circ} \mathrm{C}$ for $2 \mathrm{~h}$ did not change with time (Fig. 1). When pollen grains were suspended in a medium without CPPU $\left(0 \mathrm{mg} \cdot \mathrm{L}^{-1}\right)$, the germination rates tended to decrease with time and, after $2 \mathrm{~h}$, the rate was significantly lower than that of pollen grains not suspended in medium (Fig. 1). When pollen grains were suspended in medium with $2 \mathrm{mg} \cdot \mathrm{L}^{-1} \mathrm{CPPU}$, the pollen germination rates after $0.5,1$, and $2 \mathrm{~h}$ were significantly higher than for those in medium without CPPU (Fig. 1). Also, when pollen grains were suspended in a medium with $10 \mathrm{mg} \cdot \mathrm{L}^{-1}$ CPPU, the germination rates after $\mathrm{l}$ and $2 \mathrm{~h}$ were significant higher than for those in a medium without CPPU. The germination rates of pollen grains incubated for $2 \mathrm{~h}$ in both CPPU-containing media were almost the same as those for pollen grains not suspended in medium (Fig. 1).

According to several past reports, grape and almond pollen germination in the presence of a synthetic cytokinin was significantly lower than that of the control (Sotomayor et al., 2012; Wang et al., 2013). In this experiment, CPPU contributed to the improved viability of japanese pear pollen in suspension media. Possibly, the effect of this synthetic cytokinin on pollen grain germination may vary depending on the dose or timing of the treatment. These parameters remain to be elucidated in the near future.

EFFECTS OF SUSPENSION MEDIA ON POLLEN GRAIN VIABILITY IN THE FIELD. The pollen germination rates at the beginning of each pollination procedure in the field revealed no significant differences among the treatments in 2012 and 2013 (Fig. 2). At the end of each pollination procedure 


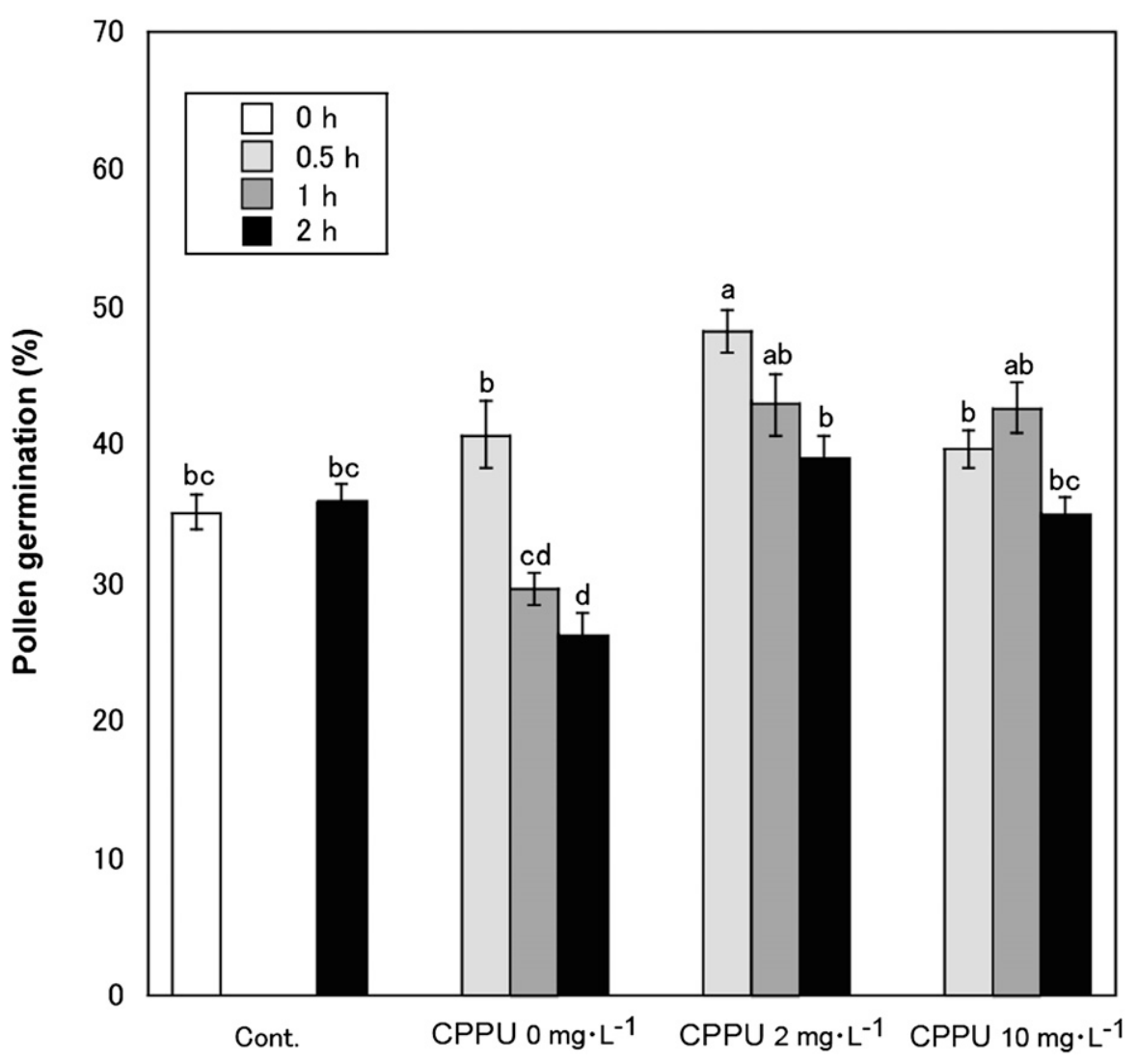

Fig. 1. Effects of forchlorfenuron (CPPU) addition on pollen germination rate in 'Hosui' japanese pear. Pollen germination was tested by measuring pollen germination rates after incubating the pollen grains in media supplemented with CPPU. The acclimatized pollen grains were suspended at $0.3 \%(\mathrm{w} / \mathrm{v})$ in media containing $10 \%(\mathrm{w} / \mathrm{v})$ sucrose and $0.1 \%(\mathrm{w} / \mathrm{v})$ agar supplemented with 0,2 , or $10 \mathrm{mg} \cdot \mathrm{L}^{-1}$ of CPPU. These suspension media were kept at $20^{\circ} \mathrm{C}\left(68.0{ }^{\circ} \mathrm{F}\right)$ for $0.5,1$, and $2 \mathrm{~h}$. As a control, the germination of pollen grains (not in medium) kept at $20{ }^{\circ} \mathrm{C}$ for 0 and $2 \mathrm{~h}$ also was tested. Three plates were used for each treatment. The germination rates were counted the number of germinated pollen grains using a microscope after $2 \mathrm{~h}$ at $25^{\circ} \mathrm{C}\left(77.0^{\circ} \mathrm{F}\right)$. Different letters above the bars within a graph indicate significant differences by Tukey-Kramer test at $P<0.05$. Vertical bars indicate SE $(\mathrm{n}=3)$; Cont. $=$ control (pollen grains acclimatized only); $1 \mathrm{mg} \cdot \mathrm{L}^{-1}=1 \mathrm{ppm}$.
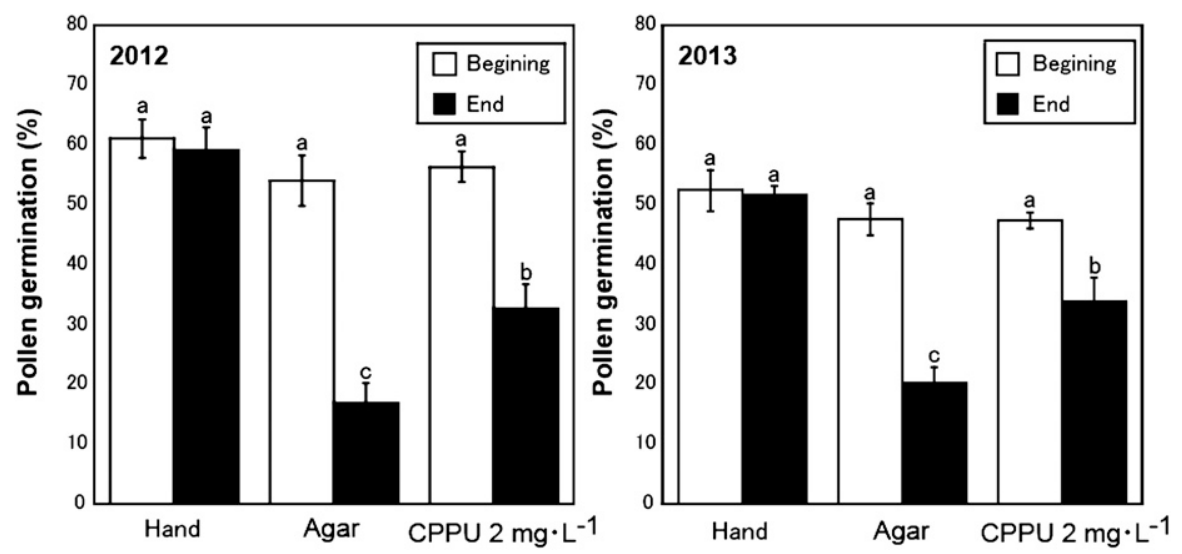

Fig. 2. Effects of forchlorfenuron concentration on pollen germination rates of 'Hosui' japanese pear in 2012 and 2013 at the beginning (white bars) and end (black bars) of pollination experiments. Different letters above the bars within a graph indicate significant differences by the Tukey-Kramer test at $P<0.05$. Vertical bars indicate SE $(n=3)$; hand $=$ hand pollination; agar $=0.1 \%$ agar; $1 \mathrm{mg} \cdot \mathrm{L}^{-1}=1 \mathrm{ppm}$. (pollination experiments took $\approx 3 \mathrm{~h}$ ), the pollen germination rates were lower than those after hand pollination, irrespective of the type of suspension media used. However, the pollen in the medium with $2 \mathrm{mg} \cdot \mathrm{L}^{-1}$ CPPU showed a significantly higher germination rate than that in the medium without CPPU at the end of the pollination procedure (Fig. 2). Therefore, CPPU may contribute to improved pollen grain viability in suspension media for practical use.

EFFECTS OF SPRAY POLLINATION ON FRUIT SET AND FRUIT QUALITY. The average percentage of fruit set per flower cluster containing five flowers for each treatment is shown in Table 1. For all treatments and years, the data shown are the averages for 60 flower clusters.

The percentages of fruit set after spray pollination without CPPU were lower than those after hand pollination in all 3 years and ranged from $48 \%$ to $72 \%$ of the hand-pollinated rate. Temperatures during and after pollination influenced the variation in the percentage of fruit set by year. In particular, fewer pollen grains adhered to the stigmata with spray pollination compared with hand pollination in crimson glory vine [Vitis coignetiae (Kimura et al., 1998)]. We assumed that spray pollination was easily affected by temperature; however, media containing CPPU gave significantly higher percentages of fruit set than media without CPPU, ranging from $71 \%$ to $106 \%$ of the hand-pollinated rate (Table 1). These results suggested that the addition of CPPU stabilized fruit set for spray pollination. In 2010 , the medium with $10 \mathrm{mg} \cdot \mathrm{L}^{-1}$ CPPU gave the highest levels of fruit set that was almost the same as that achieved by hand pollination. Nevertheless, fruit resulting from pollination with media containing 10 $\mathrm{mg} \cdot \mathrm{L}^{-1} \mathrm{CPPU}$ had abnormally thick and perpetually enlarged calyxes 21 $\mathrm{d}$ after pollination with a frequency of $\approx 100 \%$ (Fig. 3D), even though the calyx usually falls off 'Hosui' fruit by the middle of May (Fig. 3A and B). During early stages of fruit growth, CPPU or high daytime temperatures will promote cell division that can induce the calyx-perpetual trait in fruit (Watanabe et al., 2003; Zhang et al., 2008). In addition, media containing $10 \mathrm{mg} \cdot \mathrm{L}^{-1} \mathrm{CPPU}$ tended to increase the degree of fruit deformation (Fig. 3D). On the other hand, 
Table 1. Effects of suspension media and pollination methods on the rate of fruit set and number of seeds in 'Hosui' japanese pear in 2010, 2012, and 2013. Three kinds of media supplemented with 0,2 , and $10 \mathrm{mg} \cdot \mathrm{L}^{-1}$ forchlorfenuron $(\mathrm{CPPU})$ were used in the 2010 experiment. In 2012 and 2013, two kinds of media supplemented with 0 and $2 \mathrm{mg} \cdot \mathrm{L}^{-1} \mathrm{CPPU}$ were used in the experiments. All media included $0.1 \%$ agar and $10 \%$ sucrose.

\begin{tabular}{|c|c|c|c|c|c|c|c|}
\hline \multirow[b]{2}{*}{ Pollination method } & \multirow{2}{*}{$\begin{array}{l}\text { CPPU concn } \\
\left(\mathrm{mg} \cdot \mathrm{L}^{-1}\right)^{\mathrm{z}}\end{array}$} & \multicolumn{3}{|c|}{ Fruit set $(\%)^{y}$} & \multicolumn{3}{|c|}{ Seeds $[\text { no./fruit (no. fruit analyzed) }]^{x}$} \\
\hline & & 2010 & 2012 & 2013 & 2010 & 2012 & 2013 \\
\hline Spray & 0 & $36 c^{w}(48)$ & 49 c $(57)$ & $62 \mathrm{~b}(72)$ & $3.3 \mathrm{~b}(38)$ & $4.9 \mathrm{~b}(36)$ & $3.3 \mathrm{a}(35)$ \\
\hline Spray & 10 & 82 a $(106)$ & $\mathrm{L}^{\mathrm{v}}$ & - & $1.8 \mathrm{c}(57)$ & - & - \\
\hline Hand & - & 77 a $(100)$ & 86 a $(100)$ & 86 a $(100)$ & 4.6 a $(55)$ & 5.8 a $(33)$ & 2.9 a $(43)$ \\
\hline Spray (no pollen) & 2 & - & - & $29 \mathrm{c}(34)$ & - & - & $0(8)$ \\
\hline
\end{tabular}

${ }^{\mathrm{z}} 1 \mathrm{mg} \cdot \mathrm{L}^{-1}=1 \mathrm{ppm}$.

yAverage percentage of fruit set in each cluster of five flowers; 60 flower clusters counted. Fruit set of hand-pollinated flowers was set to 100 ; the other pollination methods are expressed as fold ratios compared with hand pollination and are shown in parentheses.

${ }^{x}$ Determined at harvest time.

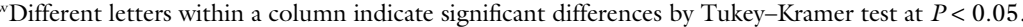

Not tested.
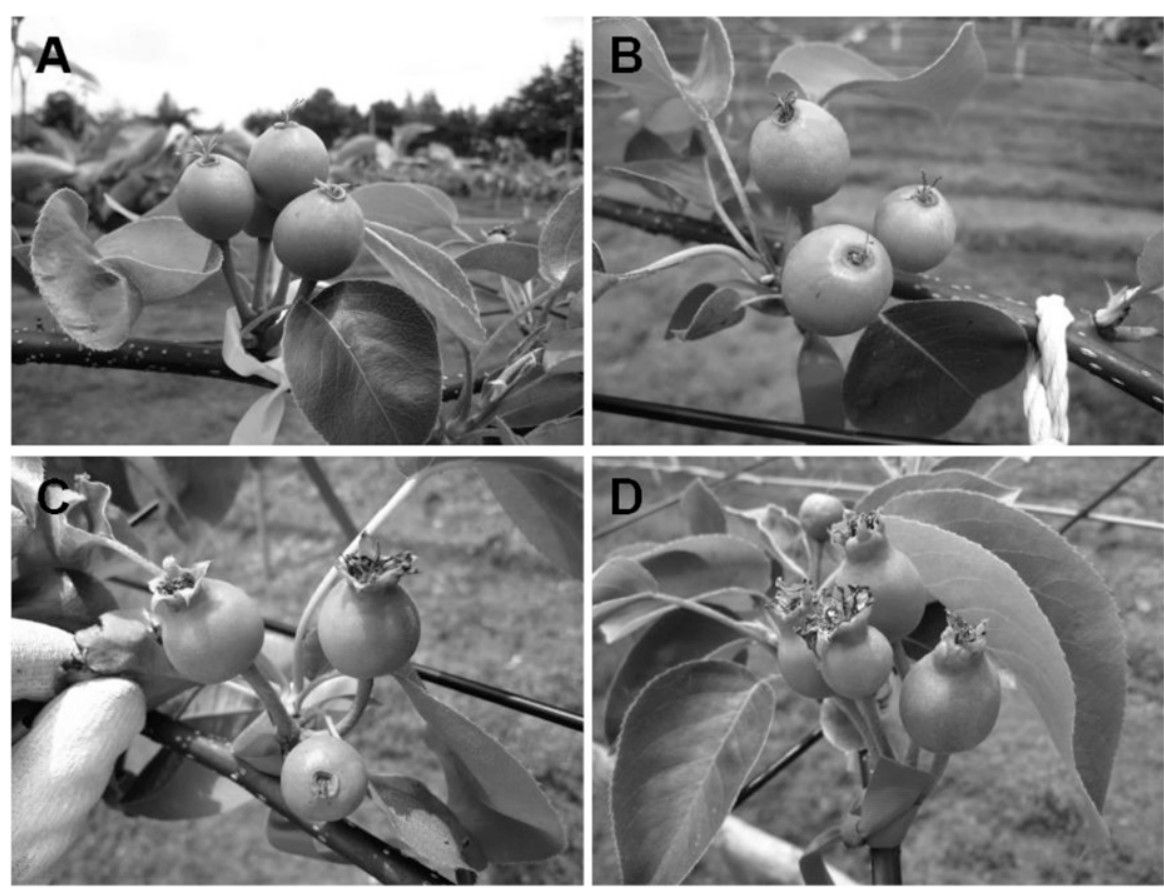

Fig. 3. Effects of forchlorfenuron (CPPU) concentration on the formation of calyx-perpetual fruit in 'Hosui' japanese pear: hand pollinated (A), CPPU $0 \mathrm{mg} \cdot \mathrm{L}^{-1}(\mathrm{~B}), \mathrm{CPPU} 2 \mathrm{mg} \cdot \mathrm{L}^{-1}(\mathrm{C})$, and CPPU $10 \mathrm{mg} \cdot \mathrm{L}^{-1}(\mathrm{D})$. All fruit were photographed at $26 \mathrm{~d}$ after full bloom; $1 \mathrm{mg} \cdot \mathrm{L}^{-1}=1 \mathrm{ppm}$.

fruit resulting from pollination with media containing $2 \mathrm{mg} \cdot \mathrm{L}^{-1} \mathrm{CPPU}$ also had a high frequency of the calyxperpetual trait, but the calyxes were normal and the fruit shape tended to be less deformed unlike the fruit pollinated with $10 \mathrm{mg} \cdot \mathrm{L}^{-1} \mathrm{CPPU}$ (Fig. 3C). In this study, we did not recognize differences in fruit shape at harvest between treatments with 2 and $10 \mathrm{mg} \cdot \mathrm{L}^{-1} \mathrm{CPPU}$; however, Niu et al. (2015) reported that a $20 \mathrm{mg} \cdot \mathrm{L}^{-1}$ CPPU treatment resulted in abnormally shaped, large fruit with extraordinarily expanded calyx tubes.
Thus, we conducted experiments focusing on media containing $2 \mathrm{mg} \cdot \mathrm{L}^{-1}$ CPPU in 2012 and 2013. Media containing $2 \mathrm{mg} \cdot \mathrm{L}^{-1} \mathrm{CPPU}$ gave significantly higher levels of fruit set than media without CPPU in all years, and fruit set levels were similar to that for hand pollination in 2013 .

Fruit quality measurements after spray pollination using media with/ without CPPU in comparison with hand pollination are shown in Table 2 . Calyx-perpetual fruit resulting from CPPU treatment significantly increased compared with the control. In addition, harvest time (average date between the first and last dates of the harvest) was delayed 3 to $7 \mathrm{~d}$ in fruit resulting from CPPU $\left(2 \mathrm{mg} \cdot \mathrm{L}^{-1}\right)$ treatment (Table 2). Notably, there were no significant differences in fruit weight among any of the pollination treatments. Furthermore, there were no significant differences among any of the treatments for the fruit shape index (except in 2012), the total soluble solids $(\%)$, or the $\mathrm{pH}$ in all 3 years. From these results, we concluded that a pollen suspension medium containing $2 \mathrm{mg} \cdot \mathrm{L}^{-1}$ of CPPU was suitable for use in spray pollinating 'Hosui' japanese pear.

Application of 20 to $100 \mathrm{mg} \cdot \mathrm{L}^{-1}$ CPPU before and during the flowering period induced partial parthenocarpic properties in pear (Niu et al., 2015; Zhang et al., 2008). Accordingly, we also investigated treatments in which the flower clusters were not artificially pollinated or the flower clusters were treated with media supplemented with $2 \mathrm{mg} \cdot \mathrm{L}^{-1}$ of CPPU only (no pollen). When the flower clusters were treated with $2 \mathrm{mg} \cdot \mathrm{L}^{-1}$ CPPU only (no pollen) in 2013 , the average fruit set was $29 \%$. On the other hand, when the flower clusters were not artificially pollinated, fruit set was not observed in any of the years. From these results, we assumed that the flowers treated with CPPU could set fruit without seeds due to the induction of parthenocarpy by CPPU. Thus, we hypothesized that the level of fruit set after spray pollinating cultivars that have weak parthenocarpic properties, like Hosui, was improved by supplementing the pollination media with CPPU. Usually, a high pollen germination rate is 


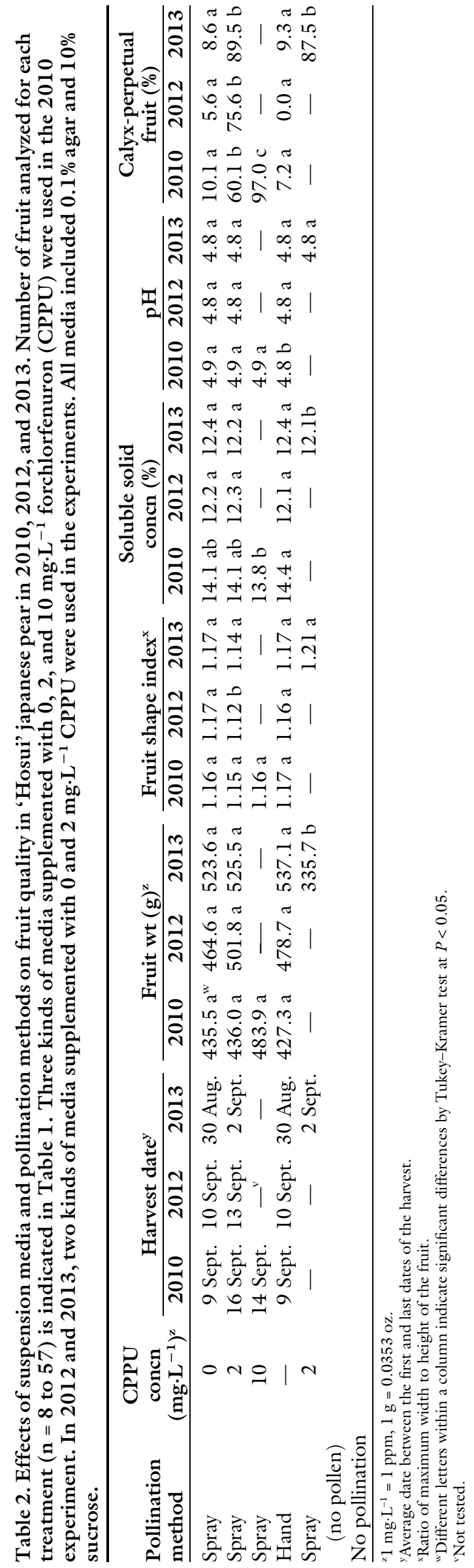

important to achieve high levels of fruit set. When pollen grains were suspended in media with CPPU, the germination rate of the pollen grains was maintained at a higher level than that without CPPU. However, the number of seeds per fruit obtained after spray pollination with CPPU was lower than that resulting from hand pollination for 2 years but not in 2013. In 2010, the number of seeds per fruit obtained after spray pollination with $10 \mathrm{mg} \cdot \mathrm{L}^{-1} \mathrm{CPPU}$ was the fewest, but the germination rate of the pollen grains after $2 \mathrm{~h}$ was the same as that using pollen grains. Our results suggest that the higher levels of fruit set by CPPU might not be due to the high germination rate of the pollen grains but due to the induction of partial parthenocarpic properties.

The numbers and sizes of seeds affect fruit enlargement and play important roles in nutrient competition among fruit in many species (Grant and Ryugo, 1984; Nitsch, 1950). However, in this study, there were no obvious differences in fruit weight, shape, or quality among the treatments in all 3 years (Table 2 ). Thus, year-to-year differences, possibly due to different weather conditions, greatly affected the number of seeds produced.

In summary, we propose that a pollen suspension medium containing $2 \mathrm{mg} \cdot \mathrm{L}^{-1}$ of CPPU is a suitable and practical method to use for the spray pollination of 'Hosui' japanese pear and will result in fruit sets of greater than $70 \%$ of that achieved by hand pollination.

\section{Literature cited}

Ainalidou, A., K. Karamanolia, U. Menkissoglu-Spiroudib, G. Diamantidisa, and T. Matsic. 2015. CPPU treatment and pollination: Their combined effect on kiwifruit growth and quality. Sci. Hort. 193:147-154.

Grant, J.A. and K. Ryugo. 1984. Influence of within-canopy shading on fruit size, shoot growth, and return bloom in kiwifruit. J. Amer. Soc. Hort. Sci. 109:799-802.

Hopping, M.E. and L.M. Simpson. 1982. Supplementary pollination of tree fruits. 3. Suspension media for kiwifruit pollen. N. Z. J. Agr. Res. 25:245-250.

Kimura, P.H., G. Okamoto, and K. Hirano. 1998. Artificial pollination in Vitis coignetiae Pulliat. Vitis 37:83-86.

Nitsch, J.P. 1950. Growth and morphogenesis of the strawberry as related to auxin. Amer. J. Bot. 37:211-215. 


\section{Research Reports}

Niu, Q., T. Wang, J. Li, Q. Yang, M. Qian, and Y. Teng. 2015. Effects of exogenous application of $\mathrm{GA}_{4+7}$ and $\mathrm{N}$-(2-chloro-4pyridyl)- $\mathrm{N}^{\prime}$-phenylurea on induced parthenocarpy and fruit quality in Pyrus pyrifolia 'Cuiguan'. Plant Growth Regulat. 76:251258

Ohara, H., D. Sakamoto, K. Ohkawa, M. Nakayama, and H. Matsui. 2005. Effects of applications of exogenous gibberellins, forchlorfenuron, streptomycin, and endogenous gibberellin-like substances on induction of seedless berries in Koshu grapes. J. Amer. Soc. Enol. Viticult. Jpn. 16:68-79. (In Japanese with English abstract).

Sakamoto, D., H. Hayama, A. Ito, Y. Kashimura, T. Moriguchi, and Y. Nakamura. 2009. Spray pollination as a labor-saving pollination system in Japanese pear [Pyrus pyrifolia (Burm.f.) Nakai.]: Development of the suspension medium. Sci. Hort. 119:280-285.
Sakamoto, D., Y. Nakamura, and S. Kusaba. 2014. Applicability of using spray pollination in two Japanese pear cultivars 'Akizuki' and 'Shuurei'. Bul. Natl. Agr. Food Res. Organization Inst. Fruit Tree Sci. 17:13-18. (In Japanese with English abstract).

Sotomayor, C., J. Castro, N. Velasco, and R. Toro. 2012. Influence of seven growth regulators on fruit set, pollen germination and pollen tube growth of almonds. J. Agr. Sci. Technol. B 2:1051-1056.

Wang, R., Z. Jiao, P. Xu, L. Chen, J. Ai, X. Liu, and Y. Yang. 2013. Bisexual flower ontogeny after chemical induction and berry characteristics evaluation in male Vitis amurensis Rupr. Sci. Hort. 162:11-19.

Watanabe, H., K. Kanehara, and K. Kojima. 2003. The effect of greenhouse temperature on the formation of deformed fruits in Japanese pear 'Kosui'. Bul. Tochigi
Agr. Expt. Sta. 52:47-54. (In Japanese with English abstract).

Watanabe, M., H. Segawa, M. Murakami, S. Sagawa, and S. Komori. 2008. Effects of plant growth regulators on fruit set and fruit shape of parthenocarpic apple fruits. J. Jpn. Soc. Hort. Sci. 77:350-357.

Yano, T., N. Miyata, and H. Matsumoto. 2007. The use of liquid pollen extender thickened with polysaccharides for artificial pollination of kiwifruit. Acta Hort. 753:415-424.

Zhang, C., U. Lee, and K. Tanabe. 2008. Hormonal regulation of fruit set, parthenogenesis induction and fruit expansion in Japanese pear. Plant Growth Regulat. 55: 231-240. 